http://ejournal.upi.edu/index.php/jaz - e-mail: jurnal.zonasi@gmail.com dan jurnal zonasi@upi.edu doi.org/10.17509/jaz.v2i3.19532

\title{
ARSITEKTUR MEDITERANIA DI INDONESIA: ADAPTASI KEMEGAHAN DAN KINERJA TERMAL BANGUNAN DARI DAERAH MEDITERANIA DALAM MENGHADAPI PERUBAHAN IKLIM DI DAERAH TROPIS LEMBAB
}

\footnotetext{
Article History:

First draft received: 30 Agustus 2019

Revised:

17 September 2019

Accepted:

1 Oktober 2019

Final proof received:

Print:

15 Oktober 2019

Online

18 Juni 2019
}

\author{
Feriza Nadiar ${ }^{1}$; Danayanti Azmi Dewi Nusantara ${ }^{2}$ \\ 1,2 Jurusan Teknik Sipil, Fakultas Teknik, Universitas Negeri Surabaya, Indonesia \\ Jalan Ketintang Surabaya, Indonesia \\ Email: ferizanadiar@unesa.ac.id ; danayantinusantara@unesa.ac.id
}

\begin{abstract}
The Mediterranean architectural style began to be a reference style in designing buildings in Indonesia since the 1990s and applied to various buildings including residential buildings because it offers an impressive aesthetic element of grandeur and its response to heat according to the origin region. The potential application of Mediterranean architectural style elements in the middle of Modern architectural style invasion can still be taken to resolve thermal problems caused by environmental issues namely climate change and global warming. This research aims to evaluate the thermal performance of Mediterranean-style residential buildings in response to the local climate and the potential adaptation of the envelope elements to Modern architectural styles using ECOTECT simulations. The results showed that a sample house with a combination of three architectural styles shows that the Mediterranean architectural style can still be used and able to compete with other architectural styles at this time by including its Mediterranean style which presents grandeur, and incorporates elements of minimalist architectural style to give a modern nuance, also implementing shading strategies from Tropical architectural styles as adaptations to the tropical climate. That house sample has the longest thermal comfort duration compared to the others, which is 8.5 hours.
\end{abstract}

Keywords: thermal building performance; building envelope; architecture style; environmental issue.

Abstrak: Gaya arsitektur Mediterania mulai menjadi referensi gaya dalam mendesain bangunan di Indonesia sejak tahun 1990an dan banyak sekali diminati serta diaplikasikan ke berbagai bangunan tidak terkecuali bangunan rumah tinggal karena menawarkan unsur estetika yang mengesankan kemegahan dan responnya terhadap iklim sekitar yang cenderung panas sesuai dengan wilayah asalnya. Potensi pengaplikasian unsur-unsur gaya arsitektur Mediterania di tengah gempuran gaya arsitektur Modern masih dapat diperhitungkan dengan tujuan untuk menyelesaikan permasalahan termal berupa peningkatan temperatur yang diakibatkan oleh isu lingkungan yaitu climate change dan global warming. Penelitian ini bertujuan untuk mengevaluasi kinerja termal bangunan rumah tinggal bergaya Mediterania dalam responnya terhadap iklim setempat dan potensi pengadaptasian elemen selubungnya terhadap gaya arsitektur Modern dengan menggunakan simulasi termal ECOTECT. Hasil penelitian menunjukkan bahwa sampel rumah dengan perpaduan tiga gaya arsitektur menunjukkan bahwa gaya arsitektur Mediterania masih bisa dipergunakan dan mampu bersaing dengan gaya arsitektur lainnya saat ini yaitu dengan memasukkan gaya Mediterania sendiri yang mempresentasikan kemegahan, dan juga memasukkan unsur gaya arsitektur Minimalis untuk memberi balutan nuansa modern, serta menerapkan strategi shading dari gaya arsitektur Tropis sebagai adaptasi dengan iklim tropis. Sampel rumah tersebut memiliki durasi kenyamanan termal paling lama dibanding yang lainnya yaitu selama 8,5 jam.

Kata Kunci: kinerja termal bangunan; selubung bangunan; gaya arsitektur; isu lingkungan. 


\section{Pendahuluan}

Pada tahun 1990an, gaya arsitektur Mediterania masuk dan mulai berkembang di Indonesia (Indraswara, 2008). Semenjak kemunculannya, gaya arsitektur Mediterania banyak sekali diminati dan diaplikasikan ke berbagai bangunan tidak terkecuali bangunan rumah tinggal hingga kini namun mengalami penurunan yang signifikan ketika gaya minimalis mulai muncul di Indonesia. Gaya arsitektur Mediterania banyak diminati karena menawarkan unsur estetika yang tidak terdapat pada gaya arsitektur lain yaitu berupa ornamen-ornamen yang di mana memiliki kesamaan dengan arsitektur khas tradisional Indonesia yang juga berornamen (Indraswara, 2008). Selain itu, gaya arsitektur Mediterania juga mengesankan kemegahan yang ditampakkan dari pilar-pilar yang menjulang dari bawah sampai atas sehingga kendati kini minat dan pengaplikasian gaya arsitektur ini tidak sebanyak dahulu, namun di kalangan tertentu masih tetap ada yang menggunakan gaya ini dalam mendesain rumah tinggalnya. Gaya arsitektur Mediterania ini sendiri merujuk pada suatu style atau gaya yang mengadaptasi arsitektur di daerah Mediterania beserta unsur-unsur pembentuk yang menjadi ciri khas nya dan sifatnya adalah hanya untuk memberikan kesan Mediterania (Indraswara, 2008). Namun terlebih dari itu, Gaya Arsitektur Mediterania ini menjadi salah satu referensi gaya dalam mendesain bangunan karena karakteristik bangunan Mediterania sendiri memang cocok untuk daerah yang beriklim panas seperti salah satunya adalah tropis lembab (Freddy H. Istanto, 1999). Dengan kata lain, pengaplikasian gaya Mediterania di Indonesia ini selain mempertimbangkan fungsi estetik juga mempertimbangkan unsur adaptasi terhadap iklim sekitar. Data yang didapat dari tahun kemunculan gaya arsitektur Mediterania hingga tahun 2011 menyebutkan bahwa sektor bangunan khususnya pemukiman mengalami penurunan angka dalam hal konsumsi energi jika dibandingkan dengan sektor industri dan komersial (Wiryomartono, 2015). Rentang tahun tersebut adalah tahun-tahun gaya arsitektur Mediterania banyak diaplikasikan terutama untuk bangunan rumah tinggal atau pemukiman sebelum gaya arsitektur Modern muncul dan berkembang.

Seiring berjalannya waktu dari sejak kemunculan gaya arsitektur Medeterania di tahun 1990an, iklim mengalami perubahan yang disebabkan oleh isu lingkungan yaitu pemanasan global yang mengakibatkan kenaikan suhu. Arsitektur Mediterania tradisional yang terdapat di wilayah Mediterania sebagian besar pengaturan kota dan juga karakteristik bangunannya disesuaikan dengan kondisi iklim yang panas (Hyde, 2008). Meskipun sama-sama panas, namun terdapat perbedaan antara iklim Indonesia dengan daerah Mediterania. Karakteristik panas di daerah Mediterania yaitu panas-kering (Hyde, 2008) sedangkan di Indonesia karakteristik panasnya yaitu panas-lembab. Sehingga, meskipun karakteristiknya mirip namun terdapat sedikit perbedaan yang nantinya berpengaruh pada kebutuhan modifikasi di beberapa elemen bangunan guna dapat beradaptasi dengan iklim di Indonesia dan mengurangi konsumsi energi. Di dalam sektor bangunan, konsumsi energi yang paling banyak digunakan yaitu untuk air conditioning (AC) dan juga lampu (Wiryomartono, 2015) dan dalam dekade terakhir, konsep Zero Energi Building (ZEB) banyak menjadi perhatian dan menjadi target utama dalam mendesain bangunan baru (Ferrante, 2012). Dalam kaitannya dengan pengurangan konsumsi energi, salah satu usaha yang dapat dilakukan yaitu dengan menganalis dan meningkatkan kinerja termal bangunan agar bangunan dapat lebih responsif terhadap heat-stress (Pisello, Castaldo, Poli, dan Cotana, 2014)(Rahmat, Prianto, dan Sasongko, 2018).

Pengadaptasian bangunan dari iklim panas-kering ke daerah panas-lembab apabila tidak meninjau kembali kesesuaian referensi desain dengan iklim panas-lembab maka akan terjadi konsep desain yang tidak sesuai dan menimbulkan efek yang negative (Hardiman, 2012). Terlebih pada permasalahan dalam pereduksian panas dan kelembaban yang masuk ke dalam bangunan yang berkaitan dengan kenyamanan termal di dalam bangunan. Dalam penelitian sebelumnya menyebutkan bahwa courtyard atau atrium yang merupakan ciri khas dari arsitektur Mediterania telah lama digunakan untuk meningkatkan kinerja termal bangunan dan memodifikasi suhu dalam ruang di daerah Mediterania dan ternyata juga sama efeknya ketika diaplikasikan pada bangunan di iklim tropis seperti Malaysia (Moosavi, Mahyuddin, dan Ab Ghafar, 2015). Selain itu, rumah di Malaysia dengan teras dan balkon berkanopi menerus hingga ke atas juga dapat menghalau penetrasi sinar matahari dan mereduksi panas yang masuk ke dalam bangunan yang di mana elemen tersebut adalah hasil adaptasi dan modifikasi dari elemen portico di arsitektur Mediterania (Hassan dan Bakhlah, 2013) (Arab, 2015). Mengenai elemen selubung lainnya, penelitian sebelumnya menyebutkan bahwa elemen atap pada arsitektur Mediterania juga merupakan elemen terpenting dalam mengatasi panas yang masuk sehingga insulasi pada elemen atap merupakan cara efektif untuk mereduksi panas yang hal tersebut juga sama dilakukan pada arsitektur Tropis (Serghides and Georgakis, 2012) (Hashemi, 2017). Dengan demikian, adaptasi dan modifikasi dari arsitektur Mediterania sesungguhnya dapat diaplikasikan ke iklim tropis lembab dengan mempertimbangkan elemen apa saja yang dapat diaplikasikan dan elemen apa saja yang tidak perlu diaplikasikan. Sehingga, meskipun telah tergilas dengan munculnya gaya arsitektur Modern, gaya arsitektur Mediterania ini seharusnya masih dapat dan layak diaplikasikan ke bangunan terutama rumah tinggal dengan 
mengkaji elemen-elemen tersebut guna meningkatkan kinerja termal bangunan dibanding awal kemunculannya dahulu untuk mengatasi permasalahan perubahan iklim yang tentunya dibalut dengan nuansa modern agar dapat bersaing dengan gaya minimalis.

Penelitian ini bertujuan untuk mengevaluasi kinerja termal bangunan rumah tinggal bergaya mediterania agar mampu beradaptasi dengan perubahan iklim yang terjadi dan mampu bersaing dengan gaya arsitektur terbaru lainnya.

\section{Metode Penelitian}

\subsection{Deskripsi Bangunan}

Subyek yang akan diteliti dalam penelitian ini yaitu selubung bangunan yang bergaya Mediterania yang mana menunjukkan ciri khas dari suatu gaya dan obyeknya adalah rumah tinggal di perumahan Surabaya, Indonesia. Dalam penelitian ini yang lebih dikaji adalah elemen-elemen pembentuk selubung kaitannya dengan kinerja termal bangunan dan sebagai bentuk adaptasi serta modifikasi dari arsitektur mediterania yang asli.

Jenis bangunan yang akan diteliti yaitu bangunan tipe rumah deret yang di mana sisi kanan dan kiri menempel satu sama lain. Dan jenis perumahan yang banyak dijumpai menerapkan gaya arsitektur Mediterania ini adalah jenis perumahan menengah ke atas dengan luas tanah sekitar 100 hingga $200 \mathrm{~m}^{2}$ dan luas bangunan sekitar 200 hingga $400 \mathrm{~m}^{2}$. Pemilik rumah pada jenis perumahan tersebut cenderung memiliki kemampuan finansial yang baik sehingga pemilihan gaya ini juga merupakan salah satu cara mempresentasikan keberadaannya melalui kesan kemegahannya. Dan dari analisa iklim kota Surabaya dapat disimpulkan bahwa bulan terpanas adalah bulan Oktober sehingga bulan Oktober dipilih untuk dilakukan penelitian sebagai perwakilan bulan terpanas. Mengenai bangunan bergaya Mediterania yang ada di Indonesia, ciri - ciri pada fasade nya menurut (Indraswara, 2008) adalah sebagai berikut:

Tabel1. Ciri - ciri Bangunan Mediterania di Indonesia

\begin{tabular}{|cl|}
\hline Elemen & \multicolumn{1}{c|}{ Ciri - ciri } \\
\hline Dinding & Menggunakan batu bata dan juga plesteran \\
\hline Atap & Pelana atau Limasan \\
\hline Peneduh & - Teritisan yang pendek pada atap \\
& - Portico \\
\hline Ornamen & - Bentuk lengkung pada antar kolom Portico \\
& - Pelapis batuan alam di bawah bangunan dan di portico \\
& - List profil di kantilevel dan fasade \\
& - Railing besi dengan motif floral pada balkon \\
\hline
\end{tabular}

Sumber: (Indraswara, 2008)

Di atas adalah ciri-ciri gaya arsitektur Mediterania secara umum yang diterapkan ke bangunan di iklim tropis dari awal kemunculannya tahun 1990 an. Seiring berjalannya waktu, unsur-unsur dan elemen-elemennya diadaptasi dan dimodifikasi. Ciri-ciri di atas adalah sebagai patokan penentuan varian-varian yang akan diteliti. Uraian metode atau pendekatan analisis yang digunakan dalam melakukan kajian dipaparkan pada bagian ini.

\subsection{Sampel Bangunan}

Untuk menyaring dan mengerucutkan banyak rumah yang masuk ke dalam kriteria, digunakan metode purposive sampling yaitu pengambilan sampel secara sengaja sesuai dengan persyaratan dan tujuan penelitian. Penyaringan dan pengerucutan dimaksudkan untuk mendapatkan 3 sampel rumah yang mewakili perkembangan arsitek gaya Mediterania. Prosentase penyaringan dan pengerucutan didasarkan kesesuaian elemen dengan ciri-ciri asli dari gaya Mediterania yang ada di Indonesia dan dibagi menjadi 3 varian yaitu A, $\mathrm{B}$, dan C. Berikut ketentuan pembagian varian :

- Varian A memiliki prosentase 85-100\% kecocokan ciri-ciri dengan arsitektur gaya Mediterania.

- Varian B memiliki prosentase 75-85\% kecocokan ciri-ciri dengan arsitektur gaya Mediterania.

- Varian C memiliki prosentase 70-75\% kecocokan ciri-ciri dengan arsitektur gaya Mediterania.

Angka prosentase didapat dari kesesuaian aspek atap, dinding dan bukaan, ornamen, dan sun shading pada tiap bangunan. Dari penjelasan dan klasifikasi di atas, dipilih 3 rumah yang mewakili masing-masing varian (Gambar 1) 

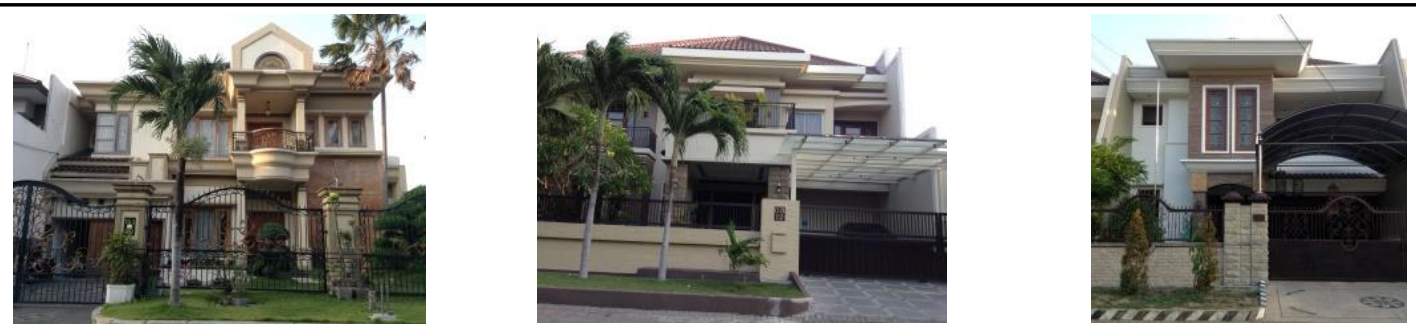

Gambar 1. 3 Sampel Rumah. (dari Kiri ke Kanan) Varian A, Varian B, Varian C (Sumber: dokumentasi pribadi, 2018)

\subsection{Kesetaraan Komparasi dan Simulasi}

Seiring dengan berkembangnya zaman yang semakin modern dan digital, penggunaan simulasi dapat mempermudah proses dan pengambilan data, mempersingkat waktu, dan memangkas biaya untuk mendapatkan dan mengolah menjadi sebuah hasil. Namun sebelum dilakukan simulasi, perlu adanya pengukuran langsung ke lapangan terhadap satu sampel rumah sebagai perwakilan verifikasi data yang nantinya akan dibandingkan dengan hasil simulasi. Proses modeling pada fase awal simulasi dilakukan penyederhanaan rumah yang memiliki luasan di atas $1000 \mathrm{~m}^{2}$. Penyederhanaan dilakukan dengan mengeleminasi ruangan-ruangan sekunder sehingga hanya tersisa ruangan primer dengan luasan yang tidak selisih jauh dengan yang lainnya. Kisaran luas yang akan dibandingkan adalah 730-864 $\mathrm{m}^{3}$ dengan lebar fasade 10-12 m. Permodelan diciptakan kondisi bangunan dan ruang se-real mungkin untuk mengetahui kondisi termal sebenarnya tanpa menggunakan pendingin udara dan mengabaikan penggunaan alat-alat elektronik lainnya.

Autodesk Ecotect Analysis digunakan sebagai software simulasi pada penelitian ini. Ecotect adalah salah satu dari beberapa alat yang analisis kinerja termal nya sederhana, cukup akurat, dan yang paling penting responsif secara visual (Sadafi, Salleh, Haw, and Jaafar, 2011). Telah banyak penelitian (Kharrufa \& Adil, 2008) (Alexandri and Jones, 2008) yang telah menggunakan software ini untuk mengevaluasi studi mereka terutama yang berhubungan dengan bangunan dan aspek lingkungannya. Dan dalam rangka lebih memperhatikan isu lingkungan, simulasi Ecotect mendapat pujian dari beberapa arsitek yang membantu mencapai desain yang mampu mengurangi potensi pemanasan global (Oduyemi and Okoroh, 2016).

\section{Hasil dan Pembahasan}

Simulasi 3 bangunan akan dibandingkan dengan menganalisa kondisi termal di dalam bangunan. Tahap pertama adalah membuat modeling ketiga bangunan dengan menggunakan kesetaraan komparasi yang telah ditentukan. Berikut adalah hasil permodelingan dari 3 bangunan terpilih yang mewakili masing-masing varian (Gambar 2).
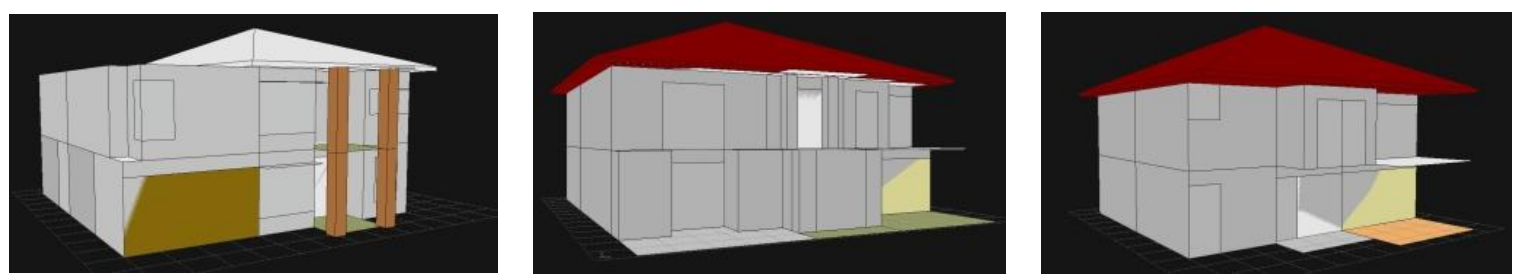

Gambar 2. Modeling 3 Bangunan. (dari Kiri ke Kanan) Varian A, Varian B, Varian C (Sumber: dokumentasi pribadi, 2018)

\subsection{Kinerja dan kenyamanan termal seluruh sampel rumah}

Hasil data profil suhu setiap jam untuk setiap sampel diproses dan dianalisis untuk membandingkan kondisi di luar dan di dalam bangunan di setiap sampel dari varian rumah. Analisis termasuk durasi kenyamanan yang terjadi di dalam bangunan dan juga pengaruh elemen selubung bangunan terhadap kondisi termal. Hasil simulasi keseluruhan ditunjukkan pada grafik Gambar 3, Gambar 4, dan Gambar 5. 


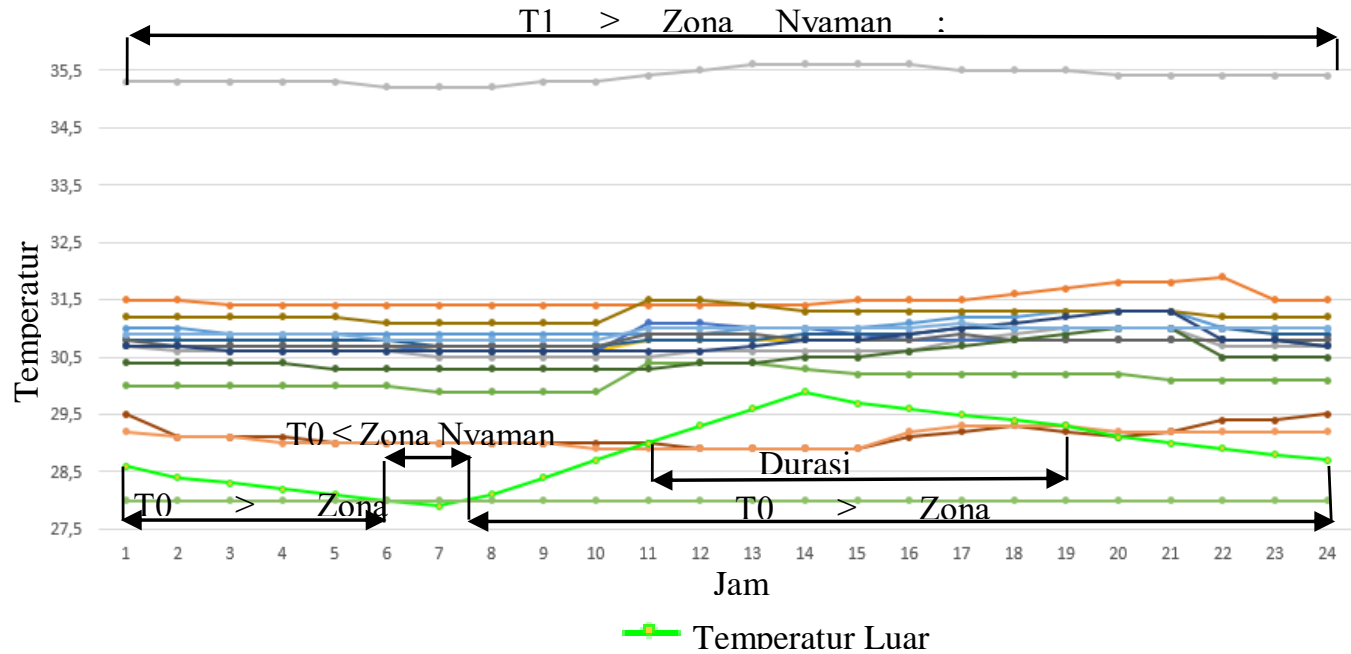

Gambar 3. Profil Temperatur perjam Varian A

(Sumber: dokumentasi pribadi, 2018)

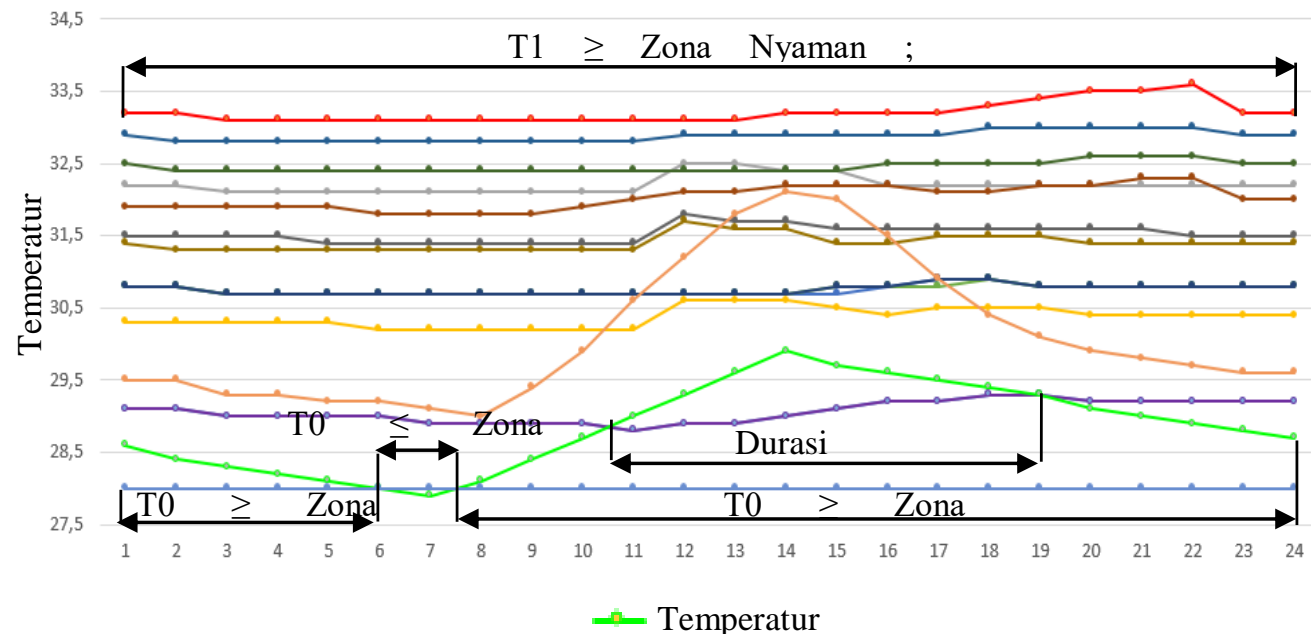

Gambar 4. Profil Temperatur perjam Varian A

(Sumber: dokumentasi pribadi, 2018)

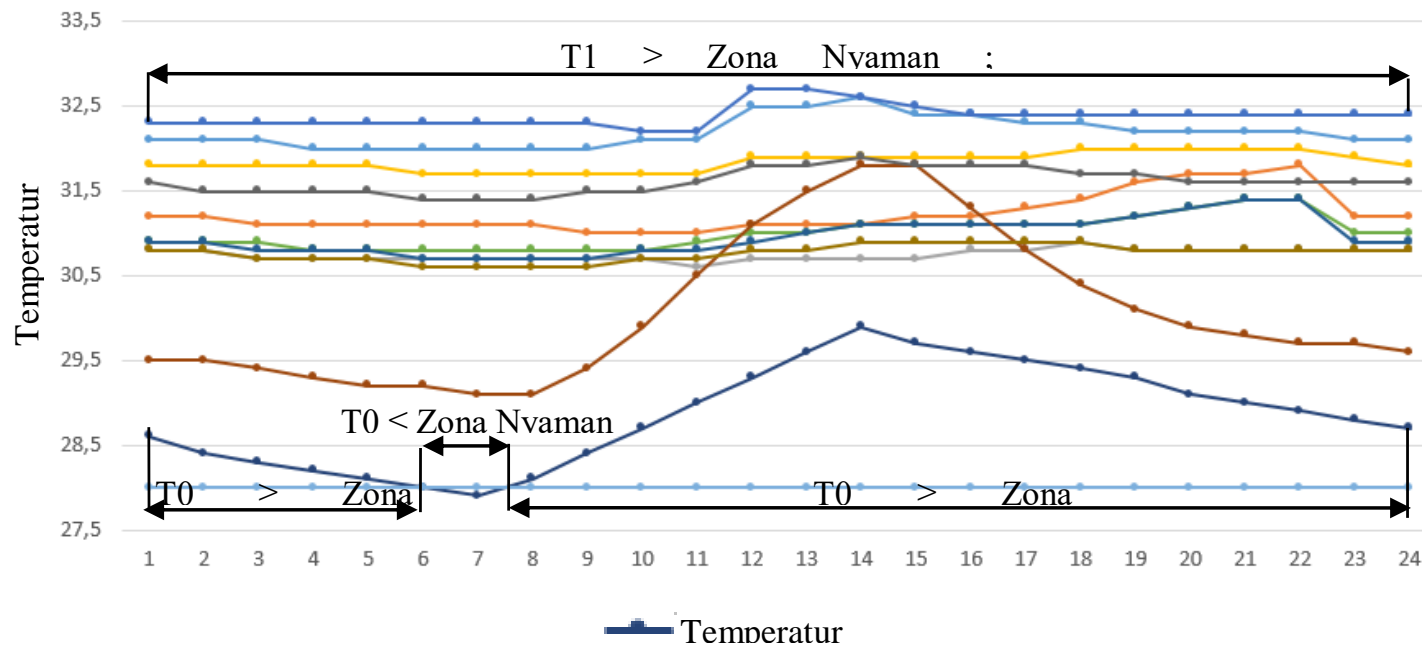

Gambar 5. Profil Temperatur perjam Varian A

(Sumber: dokumentasi pribadi, 2018) 
Pada grafik di atas, berbagai garis warna warni selain warna yang menunjukkan temperatur luar adalah garis yang mewakili setiap ruangan yang ada di dalam sebuah rumah. Dan setiap garis yang memotong garis temperatur luar dan berada di bawahnya berarti terdapat durasi kenyamanan termal karena ada ruangan di dalam rumah yang temperaturnya di bawah temperatur luar. Durasi kenyamanan termal di tiap sampel rumah berbeda-beda. Dapat dilihat pada grafik di atas, sampel varian A memiliki durasi kenyamanan termal selama 8 jam yang terjadi pada pukul 11 siang hingga pukul 7 malam. Pada sampel varian B juga terdapat durasi kenyamanan termal yaitu selama 8,5 jam yang berlangsung dari pukul 10.30 pagi hingga pukul 7 malam. Sedangkan pada sampel varian $\mathrm{C}$ tidak ditemukan adanya durasi kenyamanan termal sama sekali. Ini menunjukkan bahwa sampel rumah varian B memiliki kinerja termal paling baik diantara ketiganya. Pada penelitian sebelumnya disebutkan bahwa pengadopsian gaya arsitektur untuk diaplikasikan ke wilayah yang berbeda tanpa memodifikasinya akan menimbulkan dampak yang negatif terutama dalam beradaptasi dengan iklim sekitar (Hardiman, 2012). Dalam hal ini, sampel rumah A adalah sampel rumah yang mengaplikasikan gaya arsitektur Mediterania paling besar prosentase nya dibanding dengan yang lainnya menunjukkan kinerja termal yang cukup bagus dengan indikator terjadi durasi kenyamanan termal selama 8 jam. Hal tersebut memungkinkan terjadi karena di wilayah asal tempat gaya arsitektur Mediterania juga memiliki karakteristik panas yang hampir sama sehingga karakteristik arsitekturnya pun mencoba menyelesaikan permasalahan panas. Pada sampel rumah B, yaitu sampel rumah yang sebagian mengadaptasi dari gaya arsitektur Mediterania dan sebagian lagi mengadaptasi gaya arsitektur Modern menunjukkan kinerja termal yang ternyata lebih bagus lagi yaitu dengan indikator durasi kenyamanan termal yang selisih setengah jam lebih lama dibanding sampel rumah varian A. Sedangkan pada sampel rumah varian $C$, yaitu sampel rumah yang paling sedikit mengadaptasi gaya arsitektur Mediterania dan lebih banyak mengadaptasi gaya arsitektur Modern menunjukkan kinerja termal yang buruk diantara yang lain dengan ditunjunjukkan tidak adanya kenyamanan termal sama sekali yang terjadi di dalam rumah. Pengaplikasian gaya arsitektur Mediterania yang dipadukan dengan gaya arsitektur Modern (daam hal ini Minimalis) dan disesuaikan dengan iklim Indonesia dan Surabaya pada khususnya ternyata menciptakan bangunan yang memiliki kinerja termal lebih baik jika dibanding dengan yang hanya mengaplikasikan gaya arsitektur Mediterania. Dengan maraknya gaya arsitektur Modern, gaya arsitektur Mediterania masih memiliki potensi untuk diaplikasikan karena performa nya yang bagus pada permasalahan termal dengan memadukan gaya Minimalis maka kesan megah akan tetap didapat namun dengan sentuhan lebih modern.

\subsection{Pengaruh Elemen Selubung terhadap Kondisi Termal di dalam Bangunan}

Untuk mengetahui pengaruh elemen selubung terhadap kondisi termal di dalam bangunan, data simulasi disajikan dalam bentuk angka dan gambar grafis berupa gradasi warna. Gradasi warna dimulai dari warna biru sebagai indikator temperatur terendah hingga warna kuning sebagai indikator temperatur tertinggi. Di bawah ini disajikan data berupa grafis gradasi warna fasade tampak depan untuk mempermudah melihat dan memahami. Berikut hasil simulasi pada masing-masing sampel (Gambar 3, Gambar 4, Gambar 5).
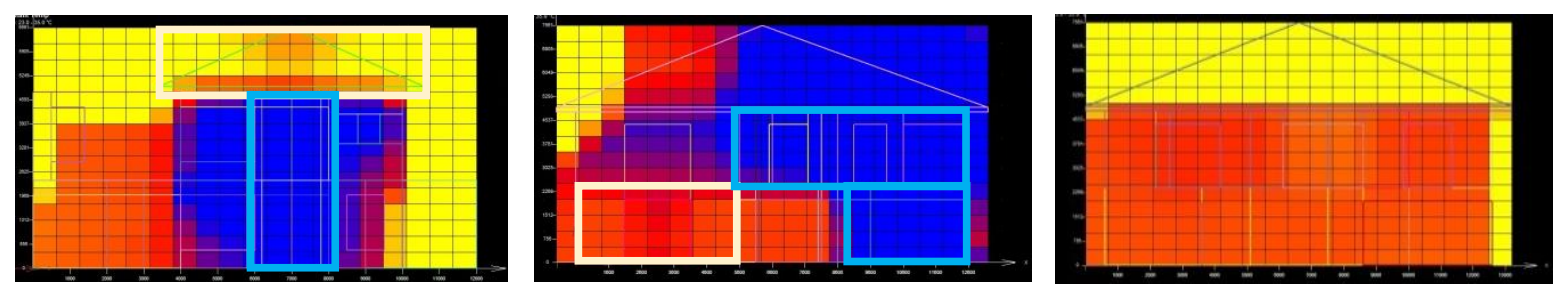

Gambar 6. Hasil Simulasi Fasade. (dari Kiri ke Kanan) Varian A, Varian B, Varian C (Sumber: dokumentasi pribadi, 2018)

Pada gambar hasil simulasi fasade di atas, kotak putih menandakan area selubung yang berkontribusi terhadap termal di dalam ruangan sedangkan kotak biru menandakan area selubung yang berkontribusi terhadap pereduksian termal. Tanda kotak biru hanya terdapat pada sampel rumah varian A dan B yang dimana keduanya juga memiliki durasi kenyamanan termal. Pada sampel rumah varian $\mathrm{A}$, kotak biru berada pada area selubung yang memiliki elemen portico yaitu elemen khas dari gaya arsitektur Mediterania berupa teras dan balkon berkanopi menerus ke atas. Elemen tersebut mampu mereduksi termal yang akan masuk ke dalam bangunan yang diindikasikan dengan warna biru pada hasil simulasi. Pada penelitian sebelumnya juga disebutkan bahwa dinding yang dilindungi oleh teras atau balkon merupakan sun shading yang efektif untuk menghalau matahari masuk penyebab permasalahan termal dalam bangunan (Arab, Hassan, \& Qanaa, 2018) 
(Arab, 2015). Pada sampel rumah varian B, area selubung yang berwarna biru dan diberi tanda kotak biru lebih luas dari pada sampel rumah varian A. Hal tersebut memberikan efek durasi kenyamanan termal yang lebih panjang pula dibanding dengan sampel rumah varian A. Area yang berwarna biru tersebut adalah area selubung yang memiliki elemen portico, teritisan, dan kanopi yang terhubung dengan kanopi carport. Ketiga elemen tersebut adalah elemen sun shading yang merupakan perpaduan dari Mediterania dan juga tropis. Hal tersebut sejalan dengan penelitian sebelumnya yaitu sun shading horizontal seperti kanopi yang terintegrasi dengan kanopi carport, teritisan, dan balkon juga efektif dalam menciptakan area pembayangan dan dapat menghalau matahari masuk sebagai penyebab termal (Hassan \& Bakhlah, 2013). Pada sampel rumah varian C, tidak ada elemen dari selubung yang berkontribusi dalam mereduksi termal sehingga tidak terdapat durasi kenyamanan termal di dalam rumah pula. Elemen kanopi pada carport tidak memberikan pengaruh seperti pada sampel rumah varian B karena tidak terintegrasi langsung dengan kanopi ataupun bangunan utama. Berdasarkan hasil pembahasan sebelumnya yaitu sampel rumah yang memiliki kinerja termal paling baik di antara yang lain adalah sampel rumah varian B yang mana dalam pembahasan ini dibuktikan bahwa elemen pembentuk selubung yang berupa sun shading tidak hanya mengaplikasikan gaya Mediterania namun juga gaya Tropis sehingga lebih dapat beradaptasi dengan iklim sekitar.

\section{Kesimpulan}

Hasil dari penelitian menemukan bahwa terdapat perbedaan pada hasil kinerja termal di ketiga varian sampel rumah. Dalam beradaptasi dengan iklim tropis lembab yaitu di Indonesia khususnya di wilayah Surabaya, sampel rumah varian B lah yang memiliki respon terhadap termal paling baik yang mana merupakan perpaduan dari 3 gaya Arsitektur. Secara tampak, terlihat gaya Mediterania dan Minimalist yang diterapkan, namun secara sistem sun shading, menerapkan sistem dari gaya arsitektur Tropis. Perpaduan ketiga gaya arsitektur ini menunjukkan bahwa gaya arsitektur Mediterania masih bisa dipergunakan dan mampu bersaing dengan gaya arsitektur lainnya saat ini yaitu dengan memasukkan gaya Mediterania sendiri yang mempresentasikan kemegahan, dan juga memasukkan unsur gaya arsitektur Minimalis untuk memberi balutan nuansa modern serta menerapkan strategi shading dari gaya arsitektur Tropis sebagai adaptasi dengan iklim tropis.

\section{Ucapan Terima Kasih}

Penulis ucapkan terimakasih kepada BMKG Surabaya dan semua pihak yang terlibat dan tidak dapat disebutkan satu persatu dalam penelitian ini.

\section{Referensi}

Alexandri, E., \& Jones, P. (2008). Temperature decreases in an urban canyon due to green walls and green roofs in diverse climates. Building and Environment, 43(4), 480-493. https://doi.org/10.1016/j.buildenv.2006.10.055

Arab, Y. (2015). Facade Design Efficiency on Extent Sunlight Penetration in Neo-Minimalist Style Apartments in Penang, Malaysia. Journal of Architectural Engineering Technology, 04(02), 2-5. https://doi.org/10.4172/2168-9717.1000147

Arab, Y., Hassan, A. S., \& Qanaa, B. (2018). Comparative Study on Shading Performance Between Traditional and Neo-Minimalist Style Apartment in Malaysia. International Transaction Journal of Engineering, Management, \& Applied Sciences \& Technologies, 9(1), 59-66.

Ferrante, A. (2012). Zero- and low-energy housing for the Mediterranean climate. Advances in Building Energy Research, 6(1), 81-118. https://doi.org/10.1080/17512549.2012.672003

Freddy H. Istanto. (1999). Telaah Gaya Arsitektur Mediterania Di Indonesia. DIMENSI (Jurnal Teknik Arsitektur), 27(1), 48-55.

Hardiman, G. (2012). Pertimbangan iklim tropis lembab dalam konsep arsitektur bangunan modern. Jurnal Arsitektur Universitas Bandar Lampung, No.2 Vol.2, 77-82.

Hashemi, A. (2017). Effects of thermal insulation on thermal comfort in low-income tropical housing. Energy Procedia, 134, 815-824. https://doi.org/10.1016/j.egypro.2017.09.535

Hassan, A. S., \& Bakhlah, M. S. O. (2013). Shading Analysis on Front Facade of Modern Terraced House Type in Petaling Jaya, Malaysia. Procedia - Social and Behavioral Sciences, 91, 13-27. https://doi.org/10.1016/j.sbspro.2013.08.396

Hyde, R. (2008). Bioclimatic Housing: Innovative Designs for Warm Climates. In R. Hyde (Ed.), Earthscan. https://doi.org/10.1177/025764301002600103 
Indraswara, M. (2008). Kajian Arsitektur Mediterania dan Perkembangannya di Indonesia. Jurnal Ilmiah Perancangan Kota Dan Permukiman, 7(2), 80-89.

Kharrufa, S. N., \& Adil, Y. (2008). Roof pond cooling of buildings in hot arid climates. Building and Environment, 43(1), 82-89. https://doi.org/10.1016/j.buildenv.2006.11.034

Moosavi, L., Mahyuddin, N., \& Ab Ghafar, N. (2015). A comparison between atrium and courtyard cooling efficiency in hot tropical climate, implementing different passive cooling strategies. Journal of Renewable and Sustainable Energy, 7(4). https://doi.org/10.1063/1.4926760

Oduyemi, O., \& Okoroh, M. (2016). Building performance modelling for sustainable building design. International Journal of Sustainable Built Environment, 5(2), 461-469. https://doi.org/10.1016/j.ijsbe.2016.05.004

Pisello, A. L., Castaldo, V. L., Poli, T., \& Cotana, F. (2014). Simulating the Thermal-Energy Performance of Buildings at the Urban Scale: Evaluation of Inter-Building Effects in Different Urban Configurations. Journal of Urban Technology, 21(1), 3-20. https://doi.org/10.1080/10630732.2014.884386

Rahmat, A., Prianto, E., \& Sasongko, S. B. (2018). Studi Evaluasi fenomena Kebakaran Pada Rumah Tinggal Di Pemukiman Padat. Jurnal Arsitektur Zonasi, 1(2), 112-122. https://doi.org/http://10.17509/jaz.v1i2.13560

Sadafi, N., Salleh, E., Haw, L. C., \& Jaafar, Z. (2011). Evaluating thermal effects of internal courtyard in a tropical terrace house by computational simulation. Energy and Buildings, 43(4), 887-893. https://doi.org/10.1016/j.enbuild.2010.12.009

Serghides, D. K., \& Georgakis, C. G. (2012). The building envelope of Mediterranean houses: Optimization of mass and insulation. Journal of Building Physics, 36(1), 83-98. https://doi.org/10.1177/1744259112448369

Wiryomartono, B. (2015). Green building and sustainable development policy in Indonesia since 2004. International Journal of Sustainable Building Technology and Urban Development, 6(2), 82-89. https://doi.org/10.1080/2093761X.2015.1025450 